УДК 616.716.4-001.514-073.756.8-089.881-74: 004.94:539.4:539.319

DOI 10.11603/2311-9624.2018.2.8999

(С). О. Гудименко, Є. В. Кузенко, Л. І. Карпенко, М. С. Скиданенко, В. В. Сікора Сумський державний університет

\title{
л-пластина як найкраща пластина для остеосинтезу ангулярного перелому нижньої щелепи
}

Резюме. Серед переломів нижньої щелепи найчастіше виникає ангулярний перелом. Частота ускладнень після остеосинтезу накісними титановими пластинами відомих конфігурацій залишається досить високою.

Мета дослідження - визначити найоптимальнішу форму титанової пластини із найбільше застосовуваних за допомогою чисельного моделювання, яке враховуватиме направлення та значення сил жувальної мускулатури.

Матеріали і методи. В якості параметрів для визначення оптимальної конфігурації пластини використовували не тільки значення напружень та площу пластини, а й відносне переміщення відламків щелепи. Для отримання тривимірної розрахункової моделі було проведено комп’ютерну томографію, яка експортувалась в програмний комплекс Ansys Workbench.

Результати досліджень та іх обговорення. У результаті досліджень ми проаналізували, що при остеосинтезі ангулярного перелому нижньої щелепи, яку ми розробили л-пластиною, найбільше зміщення уламків один відносно одного складає 0,14 мм, тобто ця пластина забезпечує надійну фіксацію уламків. Найбільше напруження, що виникло в л-пластині, склало 364 МПа. Дане напруження менше від межі текучості, а отже, при усуненні навантаження пластина буде повертатись у своє початкове положення. Необхідно відмітити, що установка пластини в інший бік дає перевищення межі текучості матеріалу.

Висновки. л-пластина, змодельована з урахуванням сили тяги жувальних м'язів, зі зменшеною кількістю металу, забезпечує найбільшу жорсткість та фіксацію уламків нижньої щелепи, що, у свою чергу, повинно поліпшити зростання переломів та зменшити частоту ускладнень після операції остеосинтезу.

Ключові слова: ангулярний перелом нижньої щелепи; напружено-деформований стан; л-пластина; остеосинтез; Ansys Workbench.

\section{Е. А. Гудыменко, Е. В. Кузенко, Л. И. Карпенко, М. С. Скиданенко, В. В. Сикора Сумской государственный университет}

\section{л-пластина как наилучшая пластина для остеосинтеза ангулярного перелома нижней челюсти}

Резюме. Среди переломов нижней челюсти чаще всего возникает ангулярный перелом. Частота осложнений после остеосинтеза накостными титановыми пластинами известных конфигураций остается достаточно высокой.

Цель исследования - определить наиболее оптимальной формы титановую пластину из наиболее часто применяемых с помощью численного моделирования, которое будет учитывать направление и значение сил жевательной мускулатуры.

Материалы и методы. В качестве параметров для определения оптимальной конфигурации пластины использовались не только значение напряжений и площадь пластины, но и относительное перемещение отломков челюсти. Для получения трехмерной расчетной модели была проведена компьютерная томография, которая экспортировалась в программный комплекс Ansys Workbench.

Результаты исследований и их обсуждение. В результате исследований мы получили, что при остеосинтезе ангулярного перелома нижней челюсти л-пластиной, разработанной нами, наибольшее смещение отломков относительно друг друга составляет 0,14 мм, то есть эта пластина обеспечивает надежную фиксацию отломков. Наибольшее напряжение, возникшее в л-пластине, составило 364 МПа. Данное напряжение меньше предела текучести, а следовательно, при устранении нагрузки пластина будет возвращаться в свое первоначальное положение. Необходимо отметить, что установка пластины в другую сторону дает превышение предела текучести материала. 
Выводы. л-пластина, смоделирована с учетом силы тяги жевательных мышц, с уменьшенным количеством металла, обеспечивает наибольшую жесткость и фиксацию отломков нижней челюсти, что, в свою очередь, должно улучшить рост переломов и уменьшить частоту осложнений после операции остеосинтеза.

Ключевые слова: ангулярный перелом нижней челюсти; напряженно-деформированное состояние; л-пластина; остеосинтез; Ansys Workbench.

\section{(C). O. Hudymenko, Ye. V. Kuzenko, L. I. Karpenko, M. S. Skydanenko, V. V. Sikora} Sumy State University

\section{$\pi$-plate as the best plate for osteosynthesis of angular mandible fracture}

Summary. An angular fracture occurs most often in the fracture of the mandible. The frequency of complications after osteosynthesis with high-quality titanium plates of known configurations remains rather high.

The aim of the study - to determine the most optimal form of the titanium plate among the most commonly used with the help of numerical simulation which takes into account the direction and value of the force of chewing muscles.

Materials and Methods. To determine the optimal configuration of the plate not only the value of the pressure and plate area were used but also the relative displacement of the mandible fractures. A computer tomography was used to obtain a three-dimensional computational model, which was exported to the Ansys Workbench software suite.

Results and Discussion. As a result of our research, we found that in the osteosynthesis of the angular mandible fracture accomplished with our $\pi$-plate, the largest displacement of the fragments relative to each other was $0.14 \mathrm{~mm}$. That means this plate provides reliable fixation of fragments. The greatest pressure that arose in the $\pi$-plate was $364 \mathrm{MPa}$. This pressure is less than the yield point therefore when the load is removed the plate returns to its original position. It should be noted that the installation of the plate in the other direction gives an excess of the material's yield point.

Key words: mandible angular fracture; the stress-deformed state; $\pi$-plate; osteosynthesis; Ansys Workbench.

Вступ. Травми лицевого відділу черепа $€$ відносно поширеними, а частота переломів нижньої щелепи (Нщ) вища порівняно 3 іншими переломами цієї ділянки обличчя. Ангулярні переломи НЩ складають від 20 до 36 \% усіх її переломів [1]. Помітно висока частота ускладнень після операції остеосинтезу виникає саме через ненадійну систему фіксації уламків щелепи [2]. Існує багато експериментальних досліджень 3 моделювання ангулярних переломів НЩ та тестувань стабільності різноманітних методів їх остеосинтезу [3]. Проте навіть найпопулярніші методи можуть не давати задовільних результатів, оскільки сухожильно-м'язовий футляр у ділянці кута Нщ та дія жувальних сил можуть призвести до зміщення уламків. Ось чому, незважаючи на прогрес в хірургічній стоматологіï, ангулярний перелом все ще дає непередбачувані результати та труднощі в лікуванні, що веде до пошуку більш ідеальних конструкцій та методів остеосинтезу $[4,5]$.
Метою дослідження було визначити найоптимальну форму титанової пластини із найбільш застосовуваних за допомогою чисельного моделювання, яке враховуватиме направлення та значення сил жувальної мускулатури.

Матеріали і методи. Комп’ютерне моделювання (КМ) часто використовують у біомеханіці, оскільки воно дає можливість дослідити об'ємний напружено-деформований стан. Також КМ дає можливість застосувати розроблені титанові пластини на великій серії віртуальних осіб, що були отримані на основі даних комп’ютерної томографії. При розробці найбільш правильної методики КМ для дослідження напружено-деформованого стану (НДС) титанових пластин для остеосинтезу ангулярного перелому НЩ необхідно визначити найбільш напружений стан, що буде виникати в пластині під час функції жування [6]. Враховуючи останнє, ми визначили спосіб закріплень та навантаження, що виникають у Нщ під дією жувальної мускулатури, а також типи 
контактів, що входять до системи «відламки щелепи-пластина-гвинти».

На початку дослідження ми побудували тривимірну модель кінцевих елементів, що базувалась на отриманому за допомогою комп’ютерної томографії зображенні НЩ. Далі в тривимірну модель за допомогою системи Solid Works ввели ангулярний перелом та скріплювальну пластину з гвинтами, а потім отриману модель імпортували в програмний комплекс ANSYS Workbench. Наступним кроком отримали НДС тривимірної моделі НЩ людини [7]. Властивості кістки прийняли ізотропними. Розрахункову модель розділили на ділянки для прикладання навантажень, що відповідають жувальним м'язам. Для розрахунків використали значення векторів дії та сили м'язів, отримані за Вебером. Дальше визначили закріплення Нщ, типи контактів, побудували розрахункову сітку та налаштували вирішувач [8].

Одним із найважливіших етапів було налаштування контактів. Ми обрали тип контакту «Frictional» між кісткою та кісткою (коефіцієнт

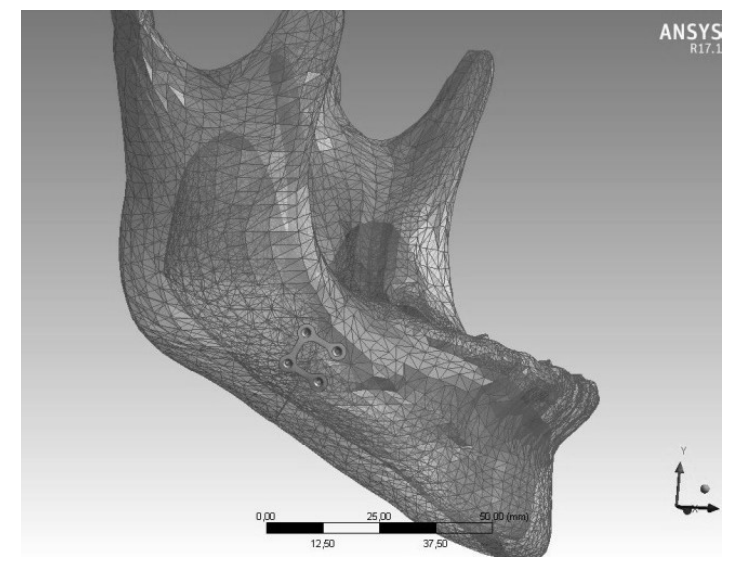

Puc. 1. Розташування л-пластини на 3D-моделі.

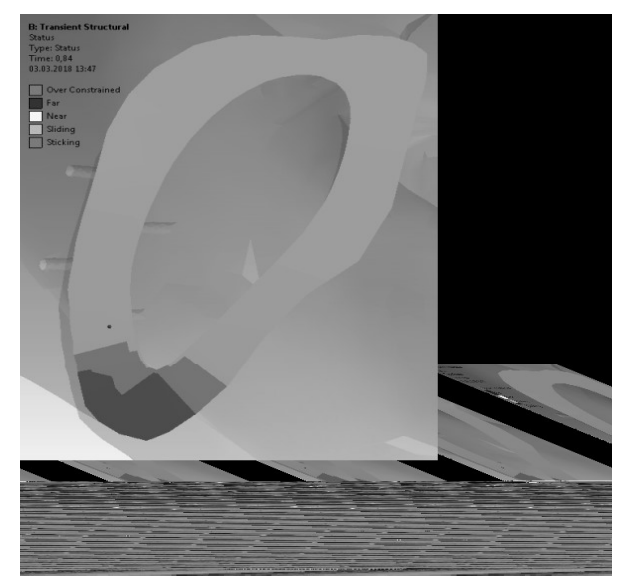

Puc. 3. Ділянка переміщення розрахункової моделі нижньої щелепи. тертя 0,5), щелепою та пластиною (коефіцієнт тертя 0,3) та гвинтами та пластиною (коефіцієнт тертя 0,15). Для вищевказаних контактних пар обрали в якості методу їх розрахунку розширений метод Лагранжу. Щоб зменшити розрахункову сітку для моделювання різьбового з'єднання між відламками кістки та гвинтами використали метод віртуальної різі, тип контакту «Bonded», метод розрахунку контактів МРC (розрахунок контактної жорсткості не проводили залежно від ітерацій).

Результати досліджень та їх обговорення. Розташування $\pi$-пластини на 3D-моделі показано на рисунку 1 , а розподіл напружень у ній - на рисунку 2.

У результаті дослідження ми визначили, що відстань, на яку два уламки НЩ, закріплені $\pi$-пластиною, зміщуються один відносно одного, складає 0,14 мм. Зона переміщення розрахункової моделі показана на рисунку 3.

Також виявили, що два уламки НЩ контактують у нижній частині, а отже, найбільший тиск буде виникати саме на цю частину кістки (рис. 4).

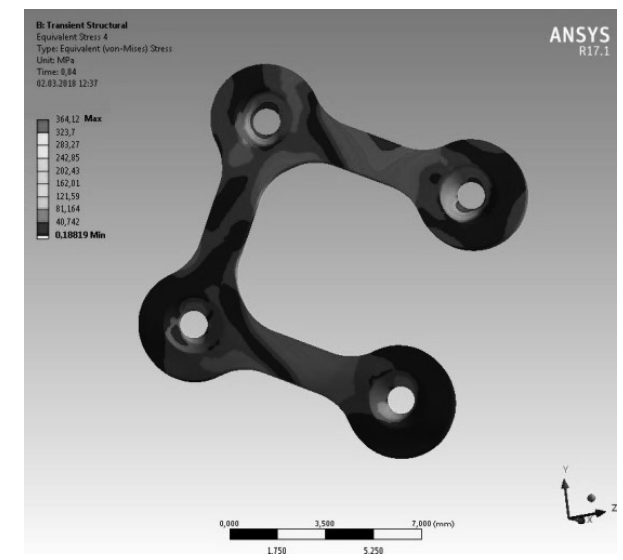

Puc. 2. Розподіл напружень в л-пластині.

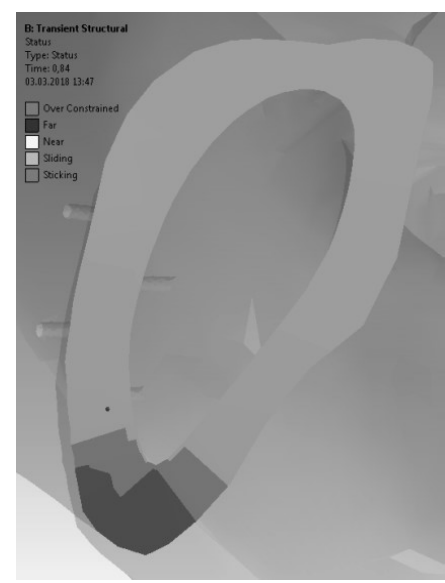

Puc. 4. Ділянка контакту двох уламків нижньої щелепи. 
Найбільше напруження, що виникло в пластині, склало 364 МПа. Воно менше від межі текучості, а отже, при усуненні навантаження пластина буде повертатись у своє початкове положення. Необхідно відмітити, що установка пластини в інший бік дає перевищення межі текучості матеріалу.

Для визначення найоптимальнішої титанової пластини для лікування ангулярного перелому НЩ, ми порівняли деякі характеристики системи «пластина-кістка» для л-пластини та пластин інших конфігурацій (прямої, пластини-квадрат та у-пластини). Отримали наступні дані:

- максимальне напруження в пластинах: пряма - 481 МПа, пластина-квадрат - 301 МПа, у-пластина - 487 МПа, л-пластина - 364 МПа;

- відстань між уламками, які зафіксовані: прямою пластиною - 0,75 мм, пластиноюквадратом - 0,13 мм, у-пластиною - 0,15 мм, $\pi$-пластиною - 0,14 мм;

\section{Список літератури}

1. Варес Я. Е. Біодеградуючі системи фіксації у травматології щелепно-лицевої ділянки: історія, сучасність, перспективи / Я. Е. Варес, О. М. Луночкіна // Практична медицина. - 2011. - № 4. - С. 36-42.

2. Biomechanical analysis of titanium fixation plates and screws in mandibular angle fractures / F. Atik, M. S. Ataç, A. Özkan [et al.] // Niger J. Clin. Pract. - 2016. - No. 19. - P. 386-390.

3. Chrcanovic B. R. Fixation of mandibular angle fractures: In vitro biomechanical assessments and computer-based studies / B. R. Chrcanovic // Oral Maxillofac Surg. - 2013. - No. 17. - P. 251-268.

4. Biomechanical comparison of different plating techniques in repair of mandibular angle fractures / A. Alkan, N. Çelebi, Ö. B. Bora, S. İnalhttp // Oral Surg. Oral Med. Oral Pathol. Oral Radiol. Endod. - 2007. - No. 104. - P. 752-775.

\section{References}

1. Vares, Ya.E. \& Lunochkina, O.M. (2011). Biodehraduiuchi systemy fiksatsiii u travmatolohiii shchelepnolytsevoi dilianky: istoriia, suchasnist, perspektyvy [Biodegradable fixation systems in traumatology of the maxillofacial area: history, modernity, perspectives]. Praktychna medytsyna - Practical Medicine, 4, 36-42 [in Ukrainian].

2. Atik, F., Ataç, M.S., Özkan, A., Kilinç, Y. \& Arslan, M. (2016). Biomechanical analysis of titanium fixation plates and screws in mandibular angle fractures. Niger J. Clin. Pract., 19, 386-390.

3. Chrcanovic, B.R. (2013). Fixation of mandibular angle fractures: In vitro biomechanical assessments and computer-based studies. Oral Maxillofac. Surg., 17, 251-268. 4. Alkan, A., Çelebi, N., Bora, Ö.B.B. \& İnalhttp, S. (2007). Biomechanical comparison of different plating techniques in repair of mandibular angle fractures. Oral Surg. Oral Med. Oral Pathol. Oral Radiol. Endod., 104, 752-775.

5. Markwardt, J., Pfeifer, G., Eckelt, U. \& Reitemeier, B.
- площа пластин: прямої - 66,9 мм², пласти-

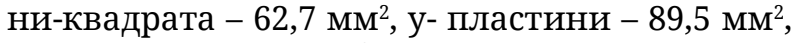
$\pi$-пластини - 56,3 мм².

Таким чином, максимальні напруження в л-пластині не перевищують межі текучості титану марки BT1-00, хоча найменші з них виникають у пластині, що має форму квадрата, проте аналіз ї̈ НДС показав, що одна з частин квадратної пластини є недовантаженою, а отже, саме ця частина не $\epsilon$ необхідною для забезпечення скріплення уламків. Враховуючи це, а також площу пластин та відстань між уламками, ми можемо стверджувати, що найоптимальнішою конструкцією титанової пластини є л-пластина.

Висновки. $\pi$-пластина, змодельована з урахуванням сили тяги жувальних м'язів, зі зменшеною кількістю металу, забезпечує найбільшу жорсткість та фіксацію уламків нижньої щелепи, що, у свою чергу, повинно поліпшити зростання переломів та зменшити частоту ускладнень після операції остеосинтезу.

5. Analysis of complications after reconstruction of bone defects involving complete mandibular resection using finite element modelling / J. Markwardt, G. Pfeifer, U. Eckelt, B. Reitemeier // Oncol. Res. Treat. - 2007. No. 30. - P. 121-126.

6. Король М. Д. Пропедевтика ортопедической стоматологии / М. Д. Король. - Винница : Нова Книга, 2012. -275 c.

7. Чуйко А. Н. Компьютерная томография и биомеханическое сопровождение в челюстно-лицевой хирургии / А. Н. Чуйко, Д. К. Калиновский, К. Р. Пограничная // Ортопед. травматол. - 2011. - № 3. - С. 29-41. 8. Бруяка В. А. Инженерный анализ в Ansys Workbench : учеб. пособ. / В. А. Бруяка, В. Г. Фокин, Я. В. Курвева. - Самара : Самар. гос. техн.ун-т, 2013. -148 c.

(2007). Analysis of complications after reconstruction of bone defects involving complete mandibular resection using finite element modelling. Oncol. Res. Treat., 30 (3), 121-126.

6. Korol, M.D. (2012). Propedevtika ortopedycheskoy stomatologii [Propaedeutics of orthopedic dentistry]. Vynnytsia: Nova Knyha [in Ukrainian].

7. Chuyko, A., Kalinovskiy, D. \& Pogranichnaya, K. (2011). Kompyuternaya tomografiya i biomekhanicheskoe soprovozhdenie $\mathrm{v}$ chelyustno-litsevoy khirurgii [Computer tomography and biomechanical support in maxillofacial surgery]. Ortoped. Travmatol. - Orthopedic Traumatology, 3, 29-41 [in Russian].

8. Bruyaka, V.A., Fokin, V.H. \& Kurveva, Ya.V. (2013). Inzhenernyy analiz $v$ Ansys Workbench: Uchebnoe posobye [Engineering analysis in Ansys Workbench: A Tutorial]. Samara: Samara State Technical University [in Ukrainian].

Отримано 05.04.18 